\title{
UNA MEMORIA DE APARIENCIAS INÉDITA DE GALDERÓN \\ Y OTROS DOCUMENTOS SOBRE LA REPRESENTACIÓN \\ DE SUS AUTOS, Y LOS DE ROJAS ZORRILLA, EN TOLEDO ENTRE 1640 Y 1645
}

Hacia 1643, don Pedro Calderón, ya vuelto de la guerra de Cataluña, se encuentra escribiendo autos sacramentales para la villa de Madrid, pero también -como se sabe- para la cercana ciudad de Toledo. Esto es algo que don Pedro hacía, por lo menos, desde 1640 -cuando envía para representar en el Corpus de la ciudad el auto Psiquis y Cupido-, aunque con altibajos, motivados justamente por el citado conflicto, al que Calderón acudió como caballero'. Por su parte, su amigo, don Francisco de Rojas Zorrilla, reúne información genealógica con el fin de obtener el hábito de Santiago, precisamente en su Toledo natal, por cuanto sus padres y sus cuatro abuelos eran naturales de la ciudad ${ }^{2}$.

Como es sabido, era costumbre acompañar los autos de lo que se denominaba una memoria de apariencias, es decir, un conjunto de instrucciones sobre la configuración de tramoyas y escenarios que el autor mandaba, generalmente de su puño y letra, para ayudar a quienes tenían que disponer los decorados y el tablado de la representación. A dichas memorias o apariencias, sin más, podían añadirse las denominadas memorias de demasías, en las

${ }^{1}$ Para la biografía de Calderón, véase Emilio Cotarelo y Mori, Ensayo sobre la vida y obras de don Pedro Calderón de la Barca, Madrid, 1924, que fue primero publicado en forma de artículos en el BRAE, 8 (1921), 9 (1922) y 10 (1923). Manejo la ed. facsímil al cuidado de I. Arellano y J. M. Escudero, Iberoamericana, Madrid, 2000.

${ }^{2}$ Se encuentran en el Archivo Histórico Nacional, Órdenes militares, Santiago, exp. 7202. Para todo lo relativo a la biografía de Rojas conviene consultar el libro del mismo Cotarelo, Don Francisco de Rojas Zorrilla, ed. facs. con introd. y notas de A. Madroñal, Real Academia de Bellas Artes y Ciencias Históricas, Toledo, 2007. 
que los encargados de organizar el escenario elaboraban una relación de las modificaciones y añadidos hechos a las memorias de apariencias con objeto de cobrar, si era el caso, una cantidad extra sobre la que en un principio se había presupuestado ${ }^{3}$. No pocos litigios tuvieron lugar por las demasias, como refieren los documentos que reproducimos aquí ${ }^{4}$.

Los estudiosos que se han ocupado de este asunto opinan que en este tipo de documentos "se encuentra información de gran utilidad para la comprensión de los autos: por un lado permiten hacerse una idea más clara del escenario en que se desarrollaban, y por otro, a menudo ofrecen datos que posibilitan resolver problemas de datación o atribución” pueden tener otras utilidades, como la de comprobar cómo el dramaturgo tenía que ajustar su obra cuando los encargados de montarla le sugerían que suprimiera ciertos elementos de difícil o imposible ejecución. Es el caso de algunos autos a los que se refieren los documentos que ahora se reproducen, relativos a su representación en el Corpus toledano de 1640 a 1645.

Por si no bastara el interés intrínseco de dichos documentos, que se conservan en el Archivo Municipal de Toledo, a ello hay que sumar uno de excepcional importancia: la desconocida e inédita hasta ahora memoria de apariencias del auto calderoniano La humildad coronada, que don Pedro representó en Toledo en 1644 junto con El socorro general. A todo ello hay que añadir, además, las memorias de apariencias de dos autos de Rojas representados, con la misma ocasión, un año después, en el escenario del Corpus toledano, y algún otro documento relacionado con los autos.

3 Véase LARA Escudero y Rafael ZAFra, Memorias de apariencias y otros documentos sobre los autos de Calderón de la Barca, Universidad de Navarra-Reichenberger, Pamplona-Kassel, 2003, p. 9.

${ }^{4}$ Para todo lo relacionado con la documentación de los autos en Madrid, aparte del clásico estudio introductorio de Bruce W. WARdropper, Introducción al teatro religioso del Siglo de Oro, Anaya, Salamanca, 1967, es imprescindible la consulta del libro de N. D. Shergold y J. E. VArey, Los autos sacramentales en Madrid en la época de Calderón. 1637-1681, Clavileño, Madrid, 1961. De los mismos autores, consúltese "Autos sacramentales in Madrid, 1644", $H R, 26$ (1958), pp. 52-63, en concreto, y "Documentos sobre los autos sacramentales en Madrid hasta 1636", RABM, 69, 1958 (manejo tirada aparte de Artes Gráficas Municipales, Madrid).

${ }^{5}$ Lara Escudero y Rafael Zafra, op. cit., p. 9. 


\section{LOS ANTECEDENTES: EL TEATRO RELIGIOSO EN TOLEDO}

No hace falta insistir en la importancia del Corpus de Toledo: ya desde el siglo $\mathrm{XV}^{6}$, cuando se documentan las primeras representaciones, hasta el siglo XVII, la catedral primada desempeña un papel protagónico pues destina importantes cantidades de dinero a la celebración de la fiesta y a la contratación de los cómicos. Lope de Rueda, por ejemplo, representa en la ciudad en diversos años ${ }^{7}$, y en el siglo que nos interesa hay que destacar los nombres de Lope de Vega y Valdivielso, a principios de siglo ${ }^{8}$, y los de Calderón y Rojas, a mediados de siglo ${ }^{9}$. Toledo defiende el dogma y ataca la heterodoxia de diversas maneras, una de ellas, y no la menos importante, es la representación de los autos sacramentales.

La catedral primada funge como organizadora y protagonista: por medio de los clérigos, en los siglos XV y Xvi ${ }^{10}$; en 1560 , y hasta 1617, por el desarrollo de la profesionalización: desde la clausura de las representaciones, en 1617, a su reapertura,

${ }^{6}$ Carmen Torroja Menéndez y María Rivas Palá, El teatro en Toledo en el siglo XV: "Auto de la Pasión" de Alonso del Campo, Real Academia Española, Madrid, 1977.

${ }^{7}$ Véase Carmen Torroja Menéndez, Catálogo del Archivo de obra y fábrica de la catedral de Toledo, Diputación Provincial, Toledo, 1977, esp. núms. 35-37 y 1324.

8 Remito a la obra clásica de Jean Louis Flecniakoska, La formation de l'“auto" religieux en Espagne avant Calderón: 1550-1635, Imp. Paul Déhan, Montpellier, 1961. También al conocido catálogo de Jenaro Alenda ofrecido en varias entregas del BRAE. Sobre los autos de LOPE, ha publicado Agustín de la Granja recientemente una documentada ed. de El bosque de amor. El labrador de la Mancha: autos sacramentales, CSIC, Madrid, 2000, y sobre José de Valdivielso conviene consultar el libro de José María Aguirre, José de Valdivielso y la poesía religiosa tradicional, Diputación Provincial, Toledo, 1965, aparte de la ed. de su Teatro completo, de R. Arias y R. Piluso, Isla, Madrid, 1975-1981.

${ }^{9}$ Remito para los autos de CALderón a la serie de ediciones del GRISO (Reichenberger, Kassel) y, en especial, a los que compuso para Toledo: $L a$ humildad coronada (ed. I. Arellano, 2002), Llamados y escogidos (eds. I. Arellano y L. Galván, 2002), El socorro general (ed. I. Arellano, 2001). Los autos de Rojas se han empezado a estudiar de forma seria en el marco del reciente Congreso Internacional IV Centenario del nacimiento de Rojas Zorrilla (Toledo, 2007, en prensa), especialmente en las ponencias de Ignacio Arellano, Carlos Mata y Miguel Zugasti. Por nuestra parte, le hemos dedicado, en el mismo Congreso, nuestra ponencia, "Rojas Zorilla y Toledo", y los trabajos: "Rojas Zorrilla representa sus autos en Toledo en 1645", en Francisco de Rojas: escenario y vida de un autor toledano, Teatro Rojas, Toledo, 2007, pp. 10-17, y "Nuevos documentos sobre Rojas Zorrilla y su teatro" y "Obras menores de Rojas Zorrilla”, ambos en el monográfico dedicado a Rojas en RLit, 69 (2007), 271-295 y 333-369.

${ }^{10}$ Véase el libro pionero de C. Torroja y M. Rivas Palá, ya citado. 
en 163711 (las razones del cierre son eclesiásticas). A partir de ese momento será el Ayuntamiento el encargado de la representación; un cierre se verifica, también, después de la muerte del príncipe, en 1646.

A principios del siglo XVII no se admitían en las iglesias toledanas, según Felipe Vallejo,

gaitas, seguidillas, pastorelas ni los poetas podían introducir en el portal interlocutores que excita[ra]n la risa, [pero] poco a poco resultó la chocarrería, el equivoquillo y la pulla, que agradaron hasta que a mitad del siglo... el maestro León introdujo en el Belén de nuestra iglesia todos los oficios, artes, ciencias ${ }^{12}$.

En 1615 se pidió la opinión de algunos catedráticos de Salamanca al respecto de estas representaciones, respondieron que eran buenas porque trataban de cosas sagradas, historias de la divina escritura, santos, etc., y porque intervenían en ellas clérigos y personas de Iglesia ${ }^{13}$. El cabildo catedralicio protestó por "los daños e indecencias de las dichas representaciones" de $1615^{14}$, por lo cual se intentaron suprimir las de 1616 , aunque sin éxito. Asimismo, la ciudad protestó ante la catedral por la supresión de los autos y siguió escenificándolos por su cuenta, delante de la Puerta del Perdón, ante lo cual la Primada exigió que su representación no coincidiera con los oficios ${ }^{15}$.

En Toledo, a principios del siglo XvII, se representaban cuatro autos en el Corpus ${ }^{16}$, pero con el paso del tiempo sólo

11 Ya habíamos publicado el documento por el que en 1617 se prohíben las representaciones en la catedral (A. MADROÑAL, Nuevos entremeses atribuidos a Luis Quiñones de Benavente, Reichenberger, Kassel, 1996, pp. 13-14). Cf., ahora, el estudio de Fernando Martínez Gil, "La expulsión de las representaciones del templo (los autos sacramentales y las crisis del Corpus de Toledo, 1613-1645)", H, 66 (2006), en esp. p. 993, donde demuestra que las representaciones del Corpus, interrumpidas en el año citado, son organizadas por el Ayuntamiento con especial relieve desde 1637 y hasta 1645, precisamente. El clásico libro de Francisco de Borja SAN Román, Lope de Vega, los cómicos toledanos y el poeta sastre, Góngora, Madrid, 1935, se detiene en 1615, como se sabe.

12 Felipe Vallejo, Memorias y disertaciones que podrán servir al que... escriba la historia de la Iglesia de Toledo, mss. 2-24 de la RAH, ff. 529-531.

${ }^{13}$ Libro Actas, f. $17 \mathrm{v}$.

14 Acuerdo de 16 de junio de 1616, Libro de actas capitulares, núm. 27, f. 134, Archivo capitular de la catedral de Toledo.

15 Acuerdo de 9 de mayo de 1617, Libro de actas capitulares, f. 232. Doy cuenta de tales documentos en mi libro Nuevos entremeses...

16 Para todo ello se puede consultar el libro de Francisco DE B. SAN Román, Lope de Vega, los cómicos... 
llegaron a verse dos autos con dos loas, dos bailes, dos entremeses y un sarao, ejecutados en diversos lugares de la catedral y, también, en plazas públicas de la ciudad. A medida que el papel organizador lo deja de tener la iglesia para cederlo a la ciudad, se sustituyen los carros móviles por los nuevos tablados fijos, que se colocan delante del Ayuntamiento y en otros sitios, como algunas plazas, la más importante de todas, Zocodover. En Toledo se habla siempre de las dos torres, como lo hacen las memorias de apariencias de Calderón y Rojas, frente a los carros móviles de Madrid y otros lugares.

En cuanto a las prácticas de la representación, los documentos consultados aclaran que la ciudad (los regidores y jurados comisionados por el Ayuntamiento) encargaba los autos a uno o varios autores: Calderón, Rojas, Blas Fernández de Mesa y otros ${ }^{17}$. Los cómicos recibían las obras un mes antes para aprenderlas y ofrecían una prueba a los comisarios; no podían salir de la ciudad y se comprometían a tener la compañía completa, así como a vestirla adecuadamente: entre ellos, citamos a Covaleda, Pedro de la Rosa y Antonio de Prado. Normalmente, recibían las obras treinta y cuatro días antes de su representación para poder estudiarlas de manera adecuada; pero no sólo se les daban los autos, también los entremeses y bailes. Eso significa que los autores de comedias no echaban mano de su repertorio, sino que recibían el conjunto. Por desgracia, no se ofrecen los títulos de entremeses ni bailes y no podemos aventurar si Calderón y Rojas mandaron también piezas breves y cómicas para acompañar los autos.

\section{Calderón y el Corpus toledano}

Sabemos que Calderón escribió expresamente varios autos para el Corpus toledano. En efecto, según Ignacio Arellano, Calderón compuso cuatro autos "relacionados con Toledo": Psiquis y

${ }^{17}$ Consúltese el trabajo de Fernando Martínez Gil, Mariano García Ruipérez y Francisco Crosas, "Calderón de la Barca y el Corpus toledano de 1640: recuperación de una carta autógrafa en el Archivo Municipal de Toledo", Criticón, 91 (2004), en esp. pp. 112-114. Sobre Fernández de Mesa, véanse los estudios que preceden a las modernas ediciones de su comedia La fundadora de la Santa Concepción: comedia en dos partes, con estudio introductorio de Nancy K. Mayberry (P. Lang, New York, 1996) y el padre Luis Vázquez (Madrid, 1997). Fernández de Mesa escribe un auto y una loa para representar en el Corpus toledano de 1640, para lo cual presenta una memoria de apariencias. 
Cupido (la versión para Toledo, hacia 1640), Llamados y escogidos (1643), La humildad coronada y El socorro general (1644)18. En 1640, la ciudad encargó a Calderón Psiquis y Cupido, y otro auto al toledano Blas Fernández de Mesa ${ }^{19}$. Más tarde, Calderón se ocupó de un auto en 1643 y de dos en 1644; sin embargo, en 1645 Rojas Zorrilla abasteció a la ciudad con los dos autos de la fiesta. Por falta de documentación en el archivo municipal, no sabemos a quién correspondieron los autos de 1641 y 1642 , ni tampoco el de 1643.

En uno de esos autos, El socorro general, Calderón se dirige a la ciudad de esta manera: "imperial patria / por hijo tuyo y por esclavo vuestro", porque su relación con Toledo por aquellos años es estrecha: el poeta vive en la ciudad y eso lo autoriza a considerarse hijo de ella. Pero, sin duda, debió de haber otros autos del Corpus toledano escritos por Calderón, como, quizá, El primer blasón de Austria, que se afirma que fue representado en Toledo, en $1635^{20}$. En efecto, leemos:
Por la brevedad del tiempo
puede pedir el poeta, en premio de sus deseos, el agrado que os desea, advertid que es hijo vuestro ${ }^{21}$.

No hay necesariamente que buscar a un autor originario de Toledo; ya hemos visto que esta fórmula era habitual en Calderón. El poeta, efectivamente, está por esas fechas en Toledo, aparece como testigo en alguno que otro documento de los que aquí se editan, como se puede leer, y quizá vive en la ciudad por esos años.

Se ha especulado que Calderón pudo escribir dos autos más para Toledo, en 1642, ya de regreso de la guerra de Cataluña. Así

${ }^{18} \mathrm{Y}$, ya fuera de la época que nos interesa, El santo rey don Fernando, primera parte (en la década de los años setenta). Véase la edición de El socorro general, de I. Arellano, Reichenberger, Kassel, 2001, p. 8.

19 Véase el art. cit. de Martínez Gil-García Ruipérez y Crosas, pp. 112-114.

20 Señala Héctor Urzáiz en su Catálogo de autores teatrales (FUE, Madrid, 2002): "Roncero, a falta de otra propuesta mejor, lo da por obra de Calderón en su reciente edición, donde una nota de Arellano cuestiona, por el contrario, tal atribución; en los versos finales, el autor parece declararse toledano".

${ }^{21}$ Sigo la ed. de V. Roncero, Reichenberger, Kassel, 1997, p. 122. 
lo señalan algunos estudiosos recientes, que dan cuenta de un documento firmado por Pedro López Briceño, el 2 de mayo de ese año, donde se menciona que las apariencias se han de hacer "como lo dicen los autos que se han de representar en la forma como lo dicen dichas memorias de don Pedro Calderón... las cuales dichas dos memorias ha visto y leído y las tiene aceptadas"22. Quizás uno de ellos fuera El primer blasón de Austria, sobre el que se daba una fecha cercana a la batalla de Nordlinguen (1634) -o inmediatamente posterior: 1635-, y que se supone representado en la propia catedral toledana ${ }^{23}$. Ahora bien, puesto que a quien se intenta glorificar es al cardenal infante, primado de dicha iglesia, y dado que el hermano de Felipe IV muere precisamente en 1641 y sus honras se celebran en Toledo un año después (como recoge un impreso de rimbombante título que se publicó describiendo dichas ceremonias: la Pira religiosa, mausoleo sacro, pompa fúnebre que la muy santa iglesia Primada de las Españas erigió devota, ostentó grande, consagró piadosa a las recientes cenizas, a las sepulcrales memorias, a las heroicas reliquias de... su alteza el serenísimo Cardenal Infante ${ }^{24}$ ), tal vez este auto podría ser uno de los escritos en ese año y su representación, auspiciada por el Ayuntamiento, pudo tener lugar cerca de la catedral, aunque no en la iglesia misma ${ }^{25}$.

Curiosamente, en dicho libro se describen las ceremonias que se llevaron a cabo con ese motivo, y entre ellas se destaca que en el lateral de la iglesia se exhibía un lienzo que representaba la batalla de Nordlinguen, y en la parte superior del mismo al Cardenal infante con "el traje como andaba en campaña, la bizarría de soldado, la valentía de general, el aire de su gala y el gusto de todos, porque pareció extremadamente" (p. 53). Como se ve, muy cercano a lo teatral; no de otra manera se representa al Cardenal infante en el auto mencionado.

Otro de esos autos pudo ser Los encantos de la culpa, representado antes de 1645, como escribe Aurora Egido, en Madrid,

22 Isabel SÁnchez-Palencia Mancebo, Fiesta y literatura en Toledo durante el siglo XVII, Universidad Complutense, Madrid, 1992, t. 1, p. 153. De la misma autora, El Corpus de Toledo durante el siglo XVII. Auto sacramental Combite de la $f e$, Imprenta Serrano, Toledo, 2005, p. 50. No he conseguido encontrar este documento en el Archivo Municipal de Toledo. Según Cotarelo, Calderón estaba en la guerra en 1641 y 1642, y no escribiría por ello ningún auto.

23 Cf. V. Roncero, ed. cit.

24 Diego Díaz de la Carrera, Madrid, 1642.

25 Pira religiosa, Madrid, 1642. Se conservan varios ejemplares, el que he consultado, en la BNM. 
aunque nada impide que lo fuera antes en Toledo ${ }^{26} \mathrm{o}$ en alguna villa cercana, como Yepes, para cuyas fiestas del Corpus habría escrito también comedias como El mágico prodigioso en $1637^{27}$. De hecho, uno de los manuscritos de dicho auto recoge en sus versos finales una alusión a la villa toledana que sustituye el nombre de Madrid, presente en los demás testimonios:
A cuyo grande milagro el mundo mil fiestas haga, y principalmente Yepes ${ }^{28}$.

Según Aurora Egido la fecha probable es 1645 o antes, porque un año después se suprimen las representaciones y porque en 1647 ya se imponían cuatro carros en lugar de dos, como aparece aquí ${ }^{29}$. La loa que antecede al auto en la edición de Pando, clave para fecharlo según Cotarelo, en realidad pertenece al auto A Dios por razón de estado ${ }^{30}$.

\section{Calderón y Rojas en Toledo}

En 1644, Rojas Zorrilla asiste a la representación de los autos del Corpus de Calderón en Toledo, y al año siguiente lo sustituye. Es posible que Calderón no estuviera interesado en componer los autos para Toledo porque ya la villa de Madrid se los había solicitado para 1645 -según documentos publicados por Shergold y Varey-, y que ante esa imposibilidad propusiera a Rojas que se encargara de la composición de dichos autos. No en vano eran amigos, recordemos que el toledano testificó, en 1646, como caballero de Santiago, sobre la muerte del hermano de don Pedro en la guerra de Cataluña ${ }^{31}$, y que, como sabemos,

26 Así lo sugieren Cotarelo y Valbuena Prat, y lo creen anterior a 1649.

27 Véase la edición de dicha comedia: Pedro CALderón de LA BARCA, El mágico prodigioso. A composite edition and study of the manuscript and printed versions, ed. M. McKendrick, Clarendon Press, Oxford, 1992, p. 1.

${ }^{28} \mathrm{El}$ ms. de la BN de París, 2 078. Véase la ed. de J. M. Escudero, pról. de A. Egido, Universidad de Navarra-Reichenberger, Pamplona-Kassel, 2004, pp. 242 y 266.

29 Aurora Egido, La fábrica de un auto sacramental: Los encantos de la culpa, Universidad, Salamanca, 1982, p. 66.

30 Como recoge el libro de Alexander Parker, citado por A. EgIDo, op. cit.

${ }^{31}$ Documento publicado por Cristóbal Pérez Pastor, Documentos para la biografía de D. Pedro Calderón de la Barca, Fortanet, Madrid, 1905, pp. 130-136. 
ambos participaron en la composición de varias comedias, de esas llamadas "en colaboración", como El jardín de Falerina, que trabajaron en compañía de otro autor.

Es indudable que Rojas y Calderón fueron, además de colaboradores, amigos ${ }^{32}$, pero también competidores. Sabemos que las comedias del toledano llegaron a gustar a los reyes, y que, algunas veces, las antepusieron a las de Calderón. Así escogieron una de ellas para inaugurar el Coliseo de Buen Retiro en 1640, que poco después representó la compañía de Bartolomé Romero, también en Toledo. Rojas era, asimismo, poeta favorito de la reina y, como tal, desplazó a otros poetas: se le encargó, por ejemplo, el vejamen dado unos años antes en el Retiro, en 1637 y $1638^{33}$.

El caso es que Rojas Zorrilla también representó sus autos en Madrid en 1639 y 1640, pero con éxito regular, según sabemos. La corte era un espacio que dominaba con don Pedro: es de sobra sabido, por la documentación aportada por otros especialistas, que en 1639 representa en la corte un par de autos: Santa María Egipciaca y El mejor huésped de España; mientras, Rojas y Antonio Coello ponen en escena uno cada uno. $\mathrm{Al}$ año siguiente, a Calderón se le encarga media fiesta en la corte -según confiesa en las memorias de apariencias de Psiquis y Cupido, que presentó en Toledo-, y compone para Madrid los autos Los misterios de la misa y El juicio final ${ }^{34}$; sin embargo, los otros dos autos se encargan a Rojas (nos referimos a El rico avariento y Las ferias de Madrid). Más adelante, será don Pedro el encargado oficial de los autos para la corte, aunque en 1641 a Rojas -que parece ocupar el puesto dejado por su amigo- se le solicitan dos: El sotillo y Sansón, uno a Vélez de Guevara y otro a Mira de Amescua ${ }^{35}$. Falta Calderón también en 1642, pero se alude a él en 1643 (quizá representó

32 Sírvanos el título de Competidores y amigos, una comedia de un enemigo declarado de don Pedro, don Antonio Sigler de Huerta. Con Calderón firma Rojas varias comedias (como apunta Cotarelo, Don Francisco de Rojas Zorrilla, p. 102) y en sana competencia ambos autores estrenan autos en el Corpus de Madrid, por ejemplo, en 1640 (N. D. Shergold y J. E. VArey, Los autos sacramentales en Madrid..., p. 28).

33 Véase la reciente ed. crítica del vejamen de 1637 de Teresa Julio, Academia burlesca que se hizo en Buen Retiro a la majestad de Filipo Cuarto el Gran$d e$, Iberoamericana, Madrid, 2007. La misma editora se ha encargado de la ed. del vejamen de 1638, en "El vejamen de Rojas para la academia de 1638. Estudio y edición”, RLit, 69 (2007), 299-332.

${ }^{34}$ Shergold y VArey, Los autos sacramentales..., p. 28.

35 Cf. ibid., p. 32. 
La sierpe de metal), aunque no tenemos constancia de que compusiera ningún auto para Madrid en el bienio de 1644-1645.

Sin duda, en los años en que se instruye el proceso para su hábito en la ciudad (1643 y 1644), Rojas asiste en Toledo a la representación de los autos del Corpus de Calderón. Así parece deducirse de la lectura de la memoria de apariencias de uno de los autos, que se reproduce más abajo: no le gusta repetir lo que ha presenciado el año anterior y por ello propone introducir alguna variedad en el escenario, más del gusto del público, aunque sólo fuera por una cuestión de variedad (véase doc. núm. 14).

Ambos autores tenían muchos puntos en común: como Rojas, Calderón obtuvo el hábito de Santiago, aunque diez años antes, y como él también tuvo que reunir información genealógica en Toledo, por tener allí a sus abuelos, tanto para la obtención de ese hábito como para el de capellán de los Reyes Nuevos en 165336. El padre de Calderón fue también escribano, y de la misma manera necesitó el poeta la dispensa papal por esa razón. Calderón y Rojas parecen compartir el medio toledano en estos años, y quizá el primero debió de aleccionar al segundo en el modo de proceder para obtener el codiciado hábito ${ }^{37}$ y proponerle que se encargara de los autos para el Corpus toledano en 1645 , fecha difícil por los cierres de los teatros. Hacia 1645, Rojas Zorrilla era persona conocida en Toledo por las citadas pruebas del hábito de Santiago ${ }^{38}$.

No hace mucho mencionábamos la existencia del documento autógrafo de Rojas en el archivo del Ayuntamiento de Toledo ${ }^{39}$ mediante el cual conocemos la memoria de apariencias que el poeta mandó, en 1645, para representar sus autos, La viña de Nabot y Galán, discreto y valiente (doc. núm. 14). El documento añade

36 Como estudiaron Eduardo Juliá Martínez primero y Jaime Colomina TORNER en varios trabajos, pero especialmente en este último, "Calderón de la Barca y Toledo", RLit, 63 (2001), 479-484.

37 Remitimos a nuestro trabajo "Rojas Zorrilla y Toledo".

${ }^{38}$ La documentación de las pruebas para el hábito de Santiago demuestra que era hombre famoso y que en Toledo no se hablaba de otra cosa en esos días; por otra parte, el poeta pasea por la ciudad en compañía de parientes como el licenciado Zorrilla o amigos, como el instructor de su proceso, don Fernando de Peralta. Por si fuera poco, va mostrando un memorial con su genealogía a diferentes testigos (véase A. MADROÑAL, "Rojas Zorrilla y Toledo").

${ }^{39}$ Véase nuestro trabajo "Autos de Rojas Zorrilla en el Corpus toledano de 1645. (Un manuscrito autógrafo en el Archivo Municipal)”, en Francisco de Rojas... 
además un dibujo de su propia mano, cuyo objeto era facilitar el trabajo a los encargados de disponer el teatro. Por la documentación que aquí reproducimos, y que obra en aquel archivo, sabemos que el autor de comedias que se ocupó de los autos de ese año fue Pedro Ascanio, que firmó un documento con fecha de 27 de mayo de 1645 (doc. núm. 19, escrito por la mano del escribano del Ayuntamiento) en el que se obligaba a hacer dos autos, dos entremeses, dos bailes, dos loas y un sarao para la fiesta de Corpus ${ }^{40}$, pero también para otras partes de la ciudad. El documento ofrece, además, curiosas noticias sobre la manera de proceder en las representaciones del Corpus toledano ${ }^{41}$.

No es raro encontrar problemas de atribución de los autos toledanos, donde se siguen relacionando los dos nombres que nos ocupan. Tómese como ejemplo el caso del auto que escribió Calderón -para el Corpus toledano de 1644-, titulado La humildad coronada, y que en la impresión que se hizo de él -bajo el nombre de Los árboles, en la recopilación Autos sacramentales al nacimiento de Cristo de 1675- se atribuyó precisamente a Rojas. De la misma forma, otros autos de Rojas se atribuyeron al autor de La vida es sueño, como El gran patio de palacio, aunque hoy parece no caber duda de la autoría del toledano ${ }^{42}$. No podemos decir lo mismo en el caso de estos dos autos mencionados de Rojas.

\section{Los documentos del Archivo Municipal de Toledo}

En el Archivo Municipal de Toledo se conserva un buen número de documentos referidos al Corpus, algunos tienen que ver con los acuerdos establecidos entre regidores y comisarios con todo tipo de oficiales y artesanos (carpinteros, músicos, ministriles...), y también, por supuesto, con los autores de comedias, que piden

40 Archivo Municipal de Toledo, Fondo histórico, caja 881. Para mayor información sobre la celebración de la fiesta en Toledo es útil el libro de Hilario Rodríguez de Gracia, El Corpus en Toledo. Fiesta religiosa y profana en los siglos XVI y XVII, Caja de Castilla-La Mancha, Toledo, 2001.

${ }^{41}$ La tesis de I. SÁnchez-Palencia Mancebo, Fiesta y literatura..., da cuenta de esta documentación del Archivo Municipal y se detiene en el documento firmado por Ascanio (t. 1, pp. 158-160), pero no menciona la memoria de apariencias de Rojas de que hablo inmediatamente.

42 Como ha demostrado Miguel Zugasti en "La estructura compositiva del pleito por alimentos en dos autos sacramentales de Rojas Zorrilla y Calderón de la Barca, El gran patio de palacio (1647) y Los alimentos del hombre (1676)”, comunicación presentada en el Congreso citado. 
licencia para representar. En algunas ocasiones encontramos memorias de apariencias que los autores de los autos enviaban para que los responsables las hicieran llegar a los cómicos que habían de estudiarlas; a los maestros de obras estaban destinadas las primeras, pues eran los encargados de disponer el tablado de la representación. Felizmente, se han conservado así las memorias de apariencias de algunos autos de Calderón: Psiquis y Cupido, Llamados y escogidos (doc. núm. 3) y La humildad coronada (doc. núm. 7); de los dos citados de Rojas Zorrilla (doc. núm. 14) y también de otros autores que ahora interesan menos, como Blas Fernández de Mesa, compañero de Calderón en el Corpus de 1640.

En estos documentos encontramos referencias a diversas obras de los autores mencionados o de otros, algunas no se han podido identificar, como la de Fernández de Mesa para el Corpus de 1640 y su correspondiente loa, de la que sólo sabemos que aparecía en ella el río Tajo. En algunas ocasiones conocemos el título de la obra, pero no es posible identificar con seguridad a qué autor pertenece, como la denominada Comedia de Tobias (doc. núm. 12), quizá pueda corresponder a una obra de Lope o a una de Rojas. En otras ocasiones sí podemos identificar con claridad la obra a la que se refieren los documentos, este es el caso de dos autos de Calderón (docs. núms. 3 y 7 ) o de Rojas (doc. núm. 14).

Por supuesto, estos documentos se refieren también a los cómicos, y ofrecen listados de compañías, algunas conocidas y otras no tanto. A veces se señalan varios nombres nuevos de actores que integran la compañía de un autor, y de los que no se tenía noticia, como es el caso del documento del 12 de marzo de 1643, referido a la compañía de Pedro de la Rosa (doc. núm. 4), o el del 9 de marzo del año siguiente, esta vez de la compañía de Antonio de Prado (doc. núm. 8).

Los documentos del Ayuntamiento toledano hablan de la decoración del espacio, de los carpinteros, de los pintores, etc., de las apariencias y las dificultades. Importa mucho señalar el léxico de especialidad que aparece en ellos, tan interesante por tantas razones, hasta el punto de componer, por sí mismo, un pequeño vocabulario que ofrece algunas palabras nuevas, o variantes de las ya sabidas, en relación con los documentos conocidos de Madrid y que hemos querido listar al final.

Por encima de todo, es interesante subrayar cómo los nuevos documentos toledanos pueden suministrar ayuda en algunos casos y hasta qué punto ofrecen datos nuevos sobre los autos 
de Calderón, completan las memorias de apariencias conocidas y añaden algún aspecto desconocido en ellas. Parece indudable que Calderón tuvo que cambiar algunos aspectos de sus obras en función de las dificultades de las apariencias que mandaba a Toledo, según se deduce de la lectura de la primera memoria de las que publicamos aquí (doc. núm. 3).

Pero los documentos más interesantes, además de las apariencias mencionadas, se refieren al toledano Rojas. En 1645, don Francisco de Rojas Zorrilla llevaba casi cinco años esperando que le concedieran el hábito de la orden de Santiago, a que le había dado derecho su matrimonio con doña Catalina Yáñez Trillo de Mendoza ${ }^{43}$, y quizá también la simpatía de Felipe IV y la reina; pero la muerte de esta última, en 1644, había originado el cierre de los teatros en la corte y una etapa de sequía para cómicos y autores. Rojas, que había vivido en Toledo muy poco tiempo, regresaba ahora dispuesto a demostrar sus nobles orígenes; pero la información que se hace sobre su familia y su nobleza es dispar: algunos testigos reconocen dicha nobleza; otros, por el contrario, la niegan aduciendo antepasados conversos, judíos y moriscos.

El caso es que Rojas manda dos memorias de apariencias y un dibujo para acompañar sus autos. Parte de ese documento de Rojas que mencionamos, del Archivo Municipal de Toledo, estaba bien localizada en un trabajo reciente ${ }^{44}$, que, sin embargo, afirma que nuestro documento no es autógrafo y señala a Mira de Amescua como autor de la comedia Galán, valiente y discreto. Pero no cabe duda de que el documento se refiere a dos autos, el casi homónimo de Rojas, Galán, discreto y valiente ${ }^{45}$, y el también

43 Véase mi trabajo "Nuevos documentos sobre Rojas Zorrilla y su teatro", RLit, 69 (2007), 271-195, donde se aportan las referencias oportunas.

44 Martínez Gil, García Ruipérez y Crosas dicen: "Del mismo autor toledano [Rojas Zorrilla] es La viña de Nabot, que posiblemente se representó en el Corpus de 1645 y cuya memoria de apariencias, no autógrafa, también se ha conservado. Asimismo, contamos con las apariencias de Galán, discreto y valiente, a buen seguro la escrita por Antonio Mira de Amescua" (art. cit., p. 107).

45 Nótese que cuando el auto se imprime en la recopilación Autos sacramentales (Antonio Francisco de Zafra, Madrid, 1675) lleva precisamente este título (f. 1), aunque en el índice de este libro figure Galán, valiente y discreto, seguramente puesto por mano ajena. Este auto se ha conservado en un solo manuscrito del siglo XviII y en dos impresos de Autos sacramentales, de 1655 y 1675 . 
suyo, titulado La viña de Nabot ${ }^{46}$, como tampoco la hay de que el documento citado sea autógrafo de este dramaturgo ${ }^{47}$. En el caso de los dos autos auténticos de Rojas, en seguida se aprecia que la memoria de apariencias escrita por éste corresponde exactamente a las circunstancias de la representación de la obra que se recogen en los manuscritos, o en la impresión de dichos autos. Las memorias están escritas con la caligrafía vacilante del poeta, no con esa otra más cuidada y propia de las copias en limpio de sus obras dramáticas como, por ejemplo, el manuscrito autógrafo de su comedia Peligrar en los remedios, que se conserva hoy en la Biblioteca Nacional ${ }^{48}$.

Si comparamos los documentos citados, llegamos a la conclusión de que no tienen nada que ver las apariencias de Rojas, que son puro esquema, con las de Calderón, mucho más demoradas e interesadas en explicar a los artesanos cómo disponer el escenario. Se diría que a Rojas le importa poco el detalle, de modo que apunta solamente algunos aspectos que le parecen fundamentales y resultan simbólicos como, por ejemplo, las cepas de uno de sus autos, de las que salen cintas de color carmesí.

Con los citados autos de Rojas de 1645 se acaba la documentación sobre festejos teatrales del Corpus en el Ayuntamiento de Toledo; parece como si un año después ya no se hubiera celebrado la fiesta en la ciudad. Las razones eran muchas y son bastante

${ }^{46}$ La viña de Nabot se conserva en dos manuscritos de la Biblioteca Nacional, uno con la signatura 17398, donde se indica que fue copiado en 1648 para la fiesta del Corpus de Granada, y otro con la signatura 15585, copiado sin duda para el Corpus toledano. Ninguno de los dos manuscritos es copia del otro, como ya indicó Américo Castro (Francisco de Rojas Zorrilla, Cada cual lo que le toca/La viña de Nabot, ed. y est. A. Castro, Centro de Estudios Históricos, Madrid, 1917, pp. 250-251), sino que proceden de un original perdido, quizás el que Rojas había mandado a Toledo. Se da la circunstancia de que el autor o-más probablemente-quien representa el auto, adecua la alusión final al lugar de representación, y así, lo que en el manuscrito que copia el texto de la representación toledana es "corona de las ziudades, / gran Toledo", se transforma en el que copia el auto para Granada, y un tanto cacofónicamente, en "corona de las ciudades, / gran Granada".

47 Para no repetir innecesariamente descripciones bibliográficas, sigo la excelente Bibliografía de Francisco de Rojas Zorrilla, que se debe a R. GonzÁlez Cañal, U. Cerezo Rubio y G. Vega García-Luengos (Reichenberger, Kassel, 2007).

48 Signatura, ms. Vitrinas, 7-6. Agradezco a mi amigo Rafael González Cañal las facilidades para consultar este y otros autógrafos de Rojas. Es de justicia agradecer la ayuda y la amabilidad del archivero municipal de Toledo, Mariano García Ruipérez, y de su equipo de facultativos. 
conocidas: la muerte de las personas reales, el cierre de los teatros, etc., pero estas razones no explican enteramente el hecho, porque ya en 1646 se empiezan a recuperar las comedias en la corte. El caso es que en una época de plena producción por parte de Calderón y Rojas Zorrilla -que siguen componiendo sus autos para Madrid-, Toledo no les vuelve a encargar ningún auto, y con ello se cierra un período extraordinario para el Corpus de Toledo que nos dejó textos de indudable valor literario, debidos a dos dramaturgos amigos.

En conclusión, creo que no es arriesgado afirmar que la ciudad de Toledo pretendía erigirse, de diferentes maneras, en defensora de la fe; una de ellas, mediante la representación de los autos sacramentales en el Corpus que -de la misma manera que los autos de fe, también representados en lugares y escenarios similares- pretendían luchar contra la herejía y ofrecían notas de actualidad histórica. Para ello, sus comisarios contrataron a los mejores dramaturgos, como Rojas Zorrilla o Calderón; este último fue el más solicitado por el Ayuntamiento toledano y no es improbable que compusiera más autos de los que hoy conocemos en el quinquenio de 1640 a 1645 .

Abraham Madroñal Consejo Superior de Investigaciones Científicas 


\section{APÉNDICE DOCUMENTAL ${ }^{1}$}

Memoria de apariencias del auto Llamados y escogidos (L. Escudero-R. Zafra, Reichenberger, Kassel, 2003, pp. 21-22). Transcripción a partir del ms. autógrafo de Calderón.

...de manera que pueda dar la vuelta y volver a escon[derse]; esto mismo sucede en la otra enramada, sino [...] lo que se descubre en ella es una nave $m u[\ldots]$ bien imitada...

...procurando i[gu]alar los pesos, de manera que pasen iguales [...]. de debajo del tablado ha de salir a su tiempo [u] na mesa grande muy bien adornada de viandas [...] y sus servicios; en medio de lla ha de haber [un] cordero

...fuentes, jarros y toallas, lo mejor que se pudiere enriquecer para adorno y vista.

"Faltan algunos fragmentos porque la hoja está rota" (según la ed. del auto Llamados y escogidos, de I. Arellano y L. Galván, Reichenberger, Kasel, 2002, p. 30).
Copia manuscrita no autógrafa del Archivo del Ayuntamiento de Toledo, fechada en 22 de abril de 1643.

...de manera que pueda dar la vuelta y volver a esconderse; esto mismo sucede en la otra enramada, sino que lo que se descubre en ella es una nave muy bien imitada...

...procurando igualar los pesos, de manera que pasen iguales. Debajo del tablado ha de salir a su tiempo una mesa grande muy bien adornada de viandas y luces y sus servicios; en medio de lla ha de haber un cordero

...fuentes, jarros y toallas, lo mejor que se pudiere enriquecer para adorno y vista.

Con lo que se advierte que la apariencia del mostruo marino no se puede escusar, ni la del caballo, y así se podrá desde luego ir mirando cómo se podrá ejecutar lo uno y lo otro en esta forma: que abriéndose un escutillón grande, descubra como unas ondas y dél salga el mostruo, tan capaz que por la boca dél pueda salir un hombre. También en otra parte se ha de descubrir otro escutillón, de donde ha de salir un

\footnotetext{
${ }^{1}$ En la transcripción de los documentos siguientes me apego a las normas de edición de textos medievales y de los Siglos de Oro, según las cuales los textos del siglo XVII se modernizan relativamente, siempre que no afecte a la fonología de las palabras. Así pues, modernizo la ortografía en lo que no tiene valor fonológico, y también actualizo acentuación, puntuación y mayúsculas, según las normas de la Real Academia Española. En cuanto a la unión y separación de palabras, adopto la norma actual, advirtiendo -sin embargo- que respeto las contracciones como deste y desarrollo vocales embebidas con corchetes; las elisiones se marcan con apóstrofo. Agradezco a Isabel Hernández Pachón, del CSIC, la ayuda prestada en la transcripción de algunos de estos documentos.
} 
peñasco hasta el tamaño que más diere lugar el espacio de la tierra y güeco, del alto del tablado; y finalmente en el aire se ha de ver el caballo con un hombre en [ ], de manera que pueda dar vuelta. Si esto tuviere inconveniente, se avise para que se vaya dispuniendo como convenga.

\section{1. [9 de abril de 1643. Obligación de unos ministriles para asistir a la fiesta del Corpus].}

Sello $4^{\circ} .10$ maravedís para el año de mil y seiscientos y cuarenta y tres.

En la ciudad de Toledo, a nueve de abril de mil y seiscientos y cuarenta y tres años, ante mí, el escribano y testigos, parecieron Alonso del Castillo y Alonso Martínez y Jerónimo Ramírez, ministriles, vecinos de Toledo.

[Espacio en blanco.]

En favor de Toledo y sus comisarios de asistir a la fiesta del Santísimo Sacramento el jueves y viernes y al ensayo y en las demás partes que se les ordenare en los dichos días y acudir cuatro ministriles, por razón de lo cual se les ha de pagar quinientos reales, más o menos lo que fuere y se hobiere pagado el año pasado, y se les ha de pagar en la forma que se pagó el año pasado.

Testigos parecidos de antes, y otros, y dichos vecinos Juan Ortiz de Montalbán, Diego de Benavente y Chaves, Alonso del Castillo, Jerónimo Ramírez, Alonso Martínez.

\section{2. [13 de abril de 1643. Juan Vidal, músico y volatín, se obliga a asistir en la fiesta del Corpus].}

Sello cuarto. 10 maravedís. Valga para el año de mil y seiscientos y cuarenta y tres.

En la ciudad de Toledo, a trece de abril de mil y seiscientos y cuarenta y tres años, ante mí, el escribano y testigos, pareció Juan Vidal, clarín, vecino de Bargas, y se obligó de asistir y servir en esta ciudad las fiestas del Santísimo Sacramento el jueves por la mañana y por la tarde, donde se hicieren las representaciones, y el viernes siguiente y en la muestra general con su clarín, y pondrá la maroma y hará las vueltas y alegrías que se acostumbra, por razón de todo lo cual le han de dar doscientos y cincuenta reales, los cien reales luego de contado, de que se otorgó por contento y pagado a su voluntad sobre que renunció las leyes de la paga y la resta el día de la fiesta, y vendrá un día antes de la muestra general a esta ciudad, donde no se pueda inviar una persona con quinientos maravedís de salario a que le traigan, y asistirá a la dicha fiesta como dicho es, si no fuere al caso que su majestad 
le ocupe o salga en su jornada, y lo cumplirá pena de veinte ducados para el Hespital del Rey desta ciudad, demás de que a su costa.

Testigos: Antonio Fernandes y Juan Días y Alonso Peres, vecinos de Toledo. Juan Ortiz de Montalbán, Juan Vidal.

\section{3. [20 de abril de 1643. Memoria de apariencias, no autógrafa, para el auto de Calderón Llamados y escogidos].}

Diez maravedís. Sello cuarto, diez maravedís, año de mil y seiscientos y cuarenta y uno.

[Al margen del párrafo: Sacóse en 2 de julio de 1641 años.]

En la ciudad de Toledo, a veinte y dos días del mes de abril de mil y seiscientos cuarenta y tres años, ante mí, el escribano mayor, pareció presente Pedro López Briceño, carpintero, vecino de Toledo, y se obligó en favor de Toledo y de los señores don Juan Fernández de la Cuadra, don Tomás Ordóñez de San Pedro, regidores, Juan Ortiz de Montalbán, Diego de Benavente, jurados, comisarios de la fiesta del Santísimo Sacramento deste año de cuarenta y tres, de hacer y que hará los tablados que se acostumbran hacer y se hicieron el año pasado de cuarenta y dos en la plaza de[1] ayuntamiento y en el corredor de la ciudad, y asimismo hará en dos partes que se le señalaren tablados, en la plaza mayor y San Vicente para la mañana de las fiestas y para las apariencias siguientes:

En lo largo de la plaza se han de hacer cuyas puertas a su tiempo se han de abrir, y desde ellas hasta el tablado de la representación han de correr dos palenques de la misma altura que el tablado; en la una enramada cuando se abra se ha de descubrir un carro triunfal grande con su trono, en lo eminente de él ha de haber una silla donde pueda venir sentada una persona y en las gradas capacidad para cuatro o cinco; al carro han de tirar al parecer cuatro animales bien imitados, los delanteros un león y un toro, los otros un ángel y un águila; todo esto se ha de mover sobre ruedas y con unas cuerdas a torno; han de llegar al tablado, donde se puedan apear los que vienen en el carro, el c[ual] ha de estar fundado sobre una viga que juegue de manera que pueda dar la vuelta y volver a escon[derse]; esto mismo sucede en la otra enramada sino que lo que se descubre en ella es una nave muy bien imitada, en cuya popa ha de venir sentada una mujer y otras cuatro o cinco personas. En lo demás del uso desta apariencia es en todo como la del carro hasta llegar, dar la vuelta y volverse, y adviértase que estas dos apariencias juegan juntas y iguales por que se prevenga gente para ellas.

En dos esquinas de las torres ha de haber dos canales encontradas, una a la parte del auditorio y otra a la del pueblo; estas han de subir hasta lo alto, donde ha de haber dos maromas cubiertas con sus mangas de nubes que pasen de una torre a otra, de manera que a un tiempo en una y en otra parte suban por los dos canales dos personas, y en llegando arriba se despeguen de ellas volando a un tiempo cada una a la otra parte, procurando i[gu]alar los pesos de manera que pasen iguales. De debajo del tablado ha de salir a 
su tiempo [u]na mesa grande muy bien adornada de viandas y luces y sus servicios; en medio de ella ha de haber [un] cordero, y todo esto ha de estar clavado de manera que pueda la mesa volverse y en lugar de todas estas viandas quedar sobre gradillas con sus luces una custodia con un cáliz y hostia. Cuando la mesa se descubre, a los lados de ella, algo distantes, salen también de debajo dos aparadores adornados de fuentes, jarros, y toallas, lo mejor que se pudiere enriquecer para adorno y vista.

Con lo que se advierte que la apariencia del mostruo marino no se puede escusar, ni la del caballo, y así se podrá desde luego ir mirando cómo se podrá ejecutar lo uno y lo otro en esta forma: que abriéndose un escutillón grande, descubra como unas ondas y dél salga el mostruo, tan capaz que por la boca dél pueda salir un hombre. También en otra parte se ha de descubrir otro escutillón, de donde ha de salir un peñasco hasta el tamaño que más diere lugar el espacio de la tierra y güeco, del alto del tablado; y finalmente en el aire se ha de ver el caballo con un hombre en [ ], de manera que pueda dar vuelta. Si esto tuviere inconveniente, se avise para que se vaya dispuniendo como convenga.

Y en conformidad de las dichas condiciones y apariencias lo ha de hacer y cumplir, por razón de lo cual se le ha de dar cuatro mil y cien reales, los dos mil reales luego, y el resto a otro día después de la fiesta, y es condición que si las apariencias de suso referidas y aquí insertas tuvieren alguna demasía más de las apariencias que se hicieron el año de cuarenta, que están insertas en la escritura que el dicho Pedro López hizo aquel año en favor de los señores comisarios de aquellas fiestas, la tal demasía la a de tasar el maestro mayor de las obras de Toledo y de las iglesias, y lo que así tasare las dichas demasías, se le ha de pagar al dicho Pedro López demás de los dichos cuatro mil y cien reales, y si hubiere menorías, se le han de usar [?] del dicho precio, y lo que montare las demasías se le han de pagar luego, y la dicha tasación se ha de hacer el día siguiente del Corpus, y si los dichos señores comisarios le dijeren haga otra cualquier obra, la ha de hacer demás de la que se hizo el año de cuarenta y se le ha de pagar por la misma tasación, y el suelo del tablado a de ser de tablas ajustadas y acepilladas, de forma que se pueda pintar en ellas, y si ha demasía se le ha de pagar. Y se hubo de hacer y cumplir todo lo de suso referido so pena que a su costa se dé a tener caro o barato, y lo que más costare se hubo de lo pagar en más las costas y daños que se siguieren, y en cuanto a ello los dichos señores comisarios y cualquiera dellos sean creídos por su cuenta [?] y por ello se le ejecuta como contrato liquidado que trae aparejado ejecución, y todo día sea complido y apremiado también cumplir, y para ello obligó su persona y bienes habidos y por haber, y los dichos señores don Juan de la Cuadra y don Tomás Ordóñez, Juan Ortiz de Montalbán y Diego de Benavides, comisarios, de mancomún y cada uno por el todo, renunciando como renunciaron las leyes de la mancomunidad, derecho de la dilación y escusión a aceptar esta escriptura, y por lo que a ellos toca se obligan de lo cumplir y pagar en la forma y como va referido, y para ello obligan sus personas y bienes habidos y por haber, y por ésta entrambas partes darán poder cumplido a cualesquier justicias y jueces designados de cualesquier partes, y especial a los desta ciudad a cuya juridición se empacha [?] todo rigor de derecho y vía ejecutoria, le compelan y apremien también cumplir como por cosa 
pasada en cosa jurada, y renunciar cualesquier leyes de su favor y la general y derechos della, y atestiguan esta carta, y lo firman de sus nombres en el registro por el dicho escribano contando a los otorgantes.

Y ésta firma Juan de Talavera y don Francisco de Galindo y Cristóbal de Madrid, vecinos de Toledo. Juan Fernández de la Cuadra, don Tomás Ordóñez y San Pedro, Juan Ortiz de Montalbán, Diego de Benavente y Chaves, Pedro López Briceño. Ante mí firmaron, de que doy fe. Melchor de Salazar, escribano mayor

\section{4. [12 de marzo de 1643. Concierto entre el autor de comedias, Pedro de la Rosa, y el arrendador del Mesón de comedias, Juan de Villalba].}

Sello $4^{\circ} .10$ maravedís. Valga para el año de mil y seiscientos y cuarenta y tres años.

En la ciudad de Toledo, doce días del mes de marzo de mil y seiscientos y cuarenta y tres años, ante mí, el escribano mayor, parecieron presentes de una parte Pedro de la Rosa, autor de comedias por su majestad, e de la otra Juan de Villalba, arrendador del Mesón de las comedias desta ciudad, y se convinieron y concertaron en que el dicho Pedro de la Rosa se obliga con su persona y bienes que tiene y tuviere, que sobre las treinta y cuatro representaciones que tiene obligación a hacer en esta ciudad antes del día del Santísimo Sacramento, conforme la escritura que hoy ha otorgado ante Melchor de Salazar, escribano mayor, cumplirá las dichas representaciones acabadas las otavas, a cincuenta, sobre las que así tuviere hechas antes del día del Corpus deste año, con la misma compañía y personajes a que está obligado hacer las fiestas del Corpus en esta ciudad, y el dicho Juan de Villalba se obligó de pagar al dicho Pedro de la Rosa de cada una de las dichas cincuenta representaciones cincuenta reales como tal arrendador del dicho corral de comedias, pagados cada día que representare, y si representare más de las dichas cincuenta representaciones, el dicho Juan de Villalba queda obligado a pagar al dicho Pedro de la Rosa a trata por cantidad las que más hiciere, y el dicho Pedro de la Rosa se obliga que por causa suya no dejará de hacer las dichas representaciones, y si faltare por causa suya de representar alguna, pagará de cada una que faltare al dicho Juan de Villalba trescientos reales, y el dicho Juan de Villalba se obliga de darle dicho corral desocupado para representar así antes de la fiesta del Corpus como acabadas las otavas, las dichas cincuenta representaciones o más si quisiere el dicho Pedro de la Rosa, sin que otro ningún autor la presente en el dicho tiempo, pena de le pagar el dicho Juan de Villalba trescientos reales por cada representación que dejare de hacer por ocuparle el dicho corral y no dársele libre el dicho Juan de Villalba. Y en esta conformidad ambas partes dijeron están convenidos y concertados, y al cumplimiento dello cada uno por lo que le toca obligaron las personas y bienes que tienen y tuvieren y dieron poder cumplido a cualesquier justicias de su majestad a quien se sometieron, y especial a las desta ciudad de Toledo, renunciando su fin, y dieron y la recurrieron por cosa pasada en cosa juzgada, renunciando leyes de su favor y la general, y lo cumplen y son a los que ven esto el señor don Fedrico Toledo [?], vecino, 
Diego de Benavente y Juan Ortiz y Juan de la Torre [?], vecinos de Toledo. Pedro de la Rosa, Juan de Villalba. Ante mí firmaron. Juan de Talavera.

\section{5. [12 de marzo de 1643]. Autor y tablado. [Concierto entre el autor de comedias Pedro de la Rosa y los jurados y regidores de Toledo].}

Sello cuarto, diez maravedís, año de mil y seiscientos y treinta y ocho.

En la ciudad de Toledo, a doce días del mes de marzo de mil y seiscientos y cuarenta y tres años, ante mí, el señor oidor, parecieron Pedro de la Rosa, autor de comedias, residente en esta ciudad, y se obligó en favor de Toledo y de los señores don Juan Fernández de la Cuadra y don Tomás Ordóñez, regidores, y Diego Benavente y Juan Ortiz de Montalbán, jurados, los comisarios, de hacer y que hará las fiestas y representaciones del día del Santísimo Sacramento deste año de cuarenta y tres, en esta manera: que'l jueves, día del Corpus, cuatro de junio por la tarde, en el sitio y como es costumbre, representará con su compañía dos auctos, dos loas, dos entremeses, dos bailes y un sarao, y por la mañana en la plaza de Zocodover en dos sitios donde se señalare, de manera que por la mañana ha de hacer dos representaciones en dos partes, y asimismo el viernes siguiente por la tarde representarán los auctos que han de representar el jueves, en la forma y como se hubieren hecho el día de la fiesta, por razón de lo cual se le han de pagar siete mil y cuatrocientos reales, los cuatro mil reales luego que diere las ofrendas bastantes para la seguridad y cumplimiento de la fiesta y la resta el viernes siguiente al jueves del Corpus, y ha de representar la dicha fiesta con las personas siguientes:

Francisco de Velasco, Pedro de la Rosa, Jacinto Becerril, Pedro de Contreras, Francisco de San Miguel, Antonio de Velasco, Juan de Tapia, Jerónimo de Morales, Cosme Pérez Gracioso, Francisco de Rojas el Rapado, Toribio de Bustamante, Catalina de la Rosa, Isabel de Góngora, Josefa Macana, María Jiménez, María de los Santos, y otra que a de recibir a satisfación de los comisarios, y los dichos señores comisarios le han de dar los autos, entremeses y bailes para que los estudien treinta y cuatro días antes del día del Corpus.

Y el dicho autor ha de poner y vestir la compañía de todo lo necesario para auto y comedia y entremeses y bailes, de trajes y lo demás que fuere necesario, y ha de estar en esta ciudad la dicha compañía treinta y cuatro días antes del Corpus, y faltando algún día, pagará XI ducados de pena por cada día, y no ha de salir desta ciudad en todos los dichos treinta y cuatro días antes del Corpus, ni entrar en esta ciudad a representar [tachado: antes del dicho] hasta el dicho tiempo, pena de quince ducados para las fiestas del Corpus desta ciudad, y todavía ser apremiado a llegar.

Y si el viernes no se hiciere en la plaza del ayuntamiento la fiesta, la ha de hacer en la parte que se le ordenare por los señores comisarios en esta ciudad, y si faltare algún representante, ha de poner a otro en su lugar a satisfación de los señores comisarios, y el dicho autor ha de poner los bailes y música y tunas que pidieren los autos y entremeses y bailes.

Las cuales dichas fiestas ha de hacer en la forma que va dicho se obliga hacer las dichas fiestas, pena de quince ducados para las fiestas del Corpus, en que se da desde luego por condenado y con cuatro ¿avéredes de ser? 
Y ésta firma Juan de Talavera, oidor, Francisco de Galindo y Juan de Villaescusa, oidores. Don Juan Fernández de la Cuadra, don Tomás Ordóñez y Sampedro, Diego de Benavente y Chaves, Juan Ortiz de Montalbán. Pedro de la Rosa

\section{6. [4 de enero de 1644. Pintura].}

Diez maravedís. Sello cuarto, diez maravedís, año de mil y seiscientos y cuarenta y cuatro.

En la ciudad de Toledo, a los cuatro días del mes de enero de mil y seiscientos y cuarenta y cuatro años, ante mí, el señor oidor, parecieron de una parte los señores don Inacio de la Palma y Juan Bernabé de Grijota, regidores, Luis de la Palma del Águila y Melchor Ortiz de Cisneros, jurados comisarios de la fiesta del Santísimo Sacramento deste año, y de otra parte Juan de Toledo, pintor, vecino desta ciudad; y estas partes dijeron que son convenidos y concertados en que el dicho Juan de Toledo se encarga de hacer y que hará toda la pintura que fuere necesaria para el adorno del teatro en que se ha de representar, en la forma contenida en la muestra que ha hecho para este efeto el señor Felipe Lázaro de Goti, maestro mayor desta santa iglesia, que ha visto, reconocido y pintado el dicho Juan de Toledo, y asimismo ha de pintar las dos nubes de las dos torres últimas y la trasmutación del jardín de las dos haces de en medio, y todo lo demás que se ofreciere y le fuere pedido por el dicho señor maestro mayor para el adorno del teatro, sin que necesiten pedírselo los caballeros comisarios, y ha de pintar las barandillas de azul y color de oro, y por toda la dicha obra, que ha[n] de ser pintados los blancos con albayalde y todo lo demás de la obra barnizado al ólio, se le han de dar por manos y colores y tachuelas para los bastidores, tres mil reales pagados en esta manera: mil reales luego de contado que recibe de los dichos señores comisarios por mano de dicho señor Luis de Palma, de que se hará ya por contado y será la entrega [...].

Y fue testigo y dio carta de pago de ello, y otros mil reales se le han de pagar cuando el dicho señor maestro mayor dijese son necesarios para proseguir la obra, y los mil reales restantes, cumplimiento a los tres mil deste contrato, se le han de pagar en libranza aceptada por Gaspar de Herrera de Cisneros, cajero de las cancillerías de Toledo, para pagarles en fin del mes de mayo deste dicho año.

Don Ignacio de la Palma. Juan Bernabé de Grijota. Luis de la Palma del Águila. Melchor Ortiz de Cisneros, Fernando Toledo.

\section{7. [18 de febrero de 1644. Memoria de apariencias no autógrafa para el auto de Calderón La humildad coronada].}

Memoria de las apariencias que se han de ejecutar en el teatro de las fiestas de el Santísimo Sacramento, conforme a la planta que queda en poder de los señores comisarios este año de 1644 .

Las dos torres que han de ser remates del teatro, han de ser correspondiente y iguales en su fábrica y pintura y los chapiteles de ellas en la confor- 
midad de la que en la planta está acabada; estos dos chapiteles a su tiempo se han de subir por elevación de canal, de manera que como vayan subiendo se vayan abriendo en hojas de nube de ocho cuarterones abriéndose en tres cuerpos que vengan a ser en todos veinte y cuatro y dentro ha de aparecer una persona. La pintura de esta nube por la parte de afuera ha de guardar, lo que se descubriere, la arquitectura de la torre y por la de dentro han de ser arreboles y celajes de cielo con sus pendientes y cortaduras de oropel que las hermoseen al tiempo que estuvieren abiertas estas dos apariencias han de corresponder en todo la una al a otra y se han de obrar a un tiempo.

Las dos torres de en medio se han de pintar de fábrica hermosa a elección de los artífices y de las colunas, ventanajes y puertas de ellas han de tener delante un follado de arriba abajo, el cual su tiempo se ha de correr y todo lo que fue fábrica y arquitectura ha [de] quedar hecho cenadores de emparrados y boscajes, advirtiéndose que esta trasmutación de más de este el primer cuerpo de entrambas torres se ha de subir de manera que quede por las tres partes de cada torre descubierto lo que se hubiere de ver en ellas y si acaso se hubiere de hacer dentro trono o peñasco u otra cosa, se avisará con tiempo; y adviértese también que estas dos apariencias se han de ejecutar a un tiempo iguales y correspondientes como las pasadas aunque en diferente ocasión.

Las dos torres de los remates de quien queda dicho que han de salir las nubes, aunque en la pintura de afuera han de guardar las proporciones de el arte, por la parte de dentro han de tener el suelo lo más alto que pudieren y dieren lugar las nubes que han de estar en ellas embebidas porque a su tiempo se han de abrir en dos mitades los bastidores que caen a los corredores y de ellas han de salir dos peñascos fundados sobre ruedas, de manera que pueda cada uno por su corredor llegar hasta la otra torre. En los remates de estos dos peñascos han de venir dos personas, la una caballera en un unicornio y la otra en un dragón de siete cabezas, y adviértese que los peñascos sean los más grandes que pudieren y los dos animales los más bien imitados y que de venir fundados sobre juego que a su tiempo pueda dar vuelta volviendo las caras los animales y las personas que han de venir en ellos para entrarse por la parte donde salieron.

Debajo de el arco de las dos torres de en medio se ha de abrir un escotillón grande y por debajo de el tablado han de salir un trono con sus gradas y en el remate de él una silla y en ella sentada una persona. La pintura de este trono ha de ser jaspes y bronces y en lo más majestuoso y g[ran]de que se pueda, advirtiendo que el escotillón no ha de estar de medio a medio, sino inclinado a la parte de afuera porque se pueda ver de todas partes.

Por lo alto de el arco han de bajar a su tiempo dos personas, las cuales han de traer entre las dos una corona imperial, y volviéndose a subir la corona se ha de quedar pendiente en el aire hasta que alargándose la cuerda pueda recebirla una persona que ha de estar en el tablado.

Todo el tablado de la representación se ha de volver a su tiempo en cuatro cuadros, los cuales han de estar adornados de flores y dibujos de jardín; en sus encañados por [...] y en medio de cada cuadro, una fuente que a su tiempo ha de correr, y en el punto de los cuatro cuadros ha de subir por debajo de el tablado una fuente grande en que pueda venir un niño por remate de ella, el cual ha de traer un instrumento en la mano, de quien ha de salir agua a su tiempo. Y todo en la conformidad que queda tratado y si 
en algo se hallare inconveniente se avisará para que se acuda a la enmienda. En Toledo, 18 de febrero de $1644^{2}$.

\section{8. [9 de marzo de 1644. Obligación del autor Antonio de Prado en nombre de su compañía].}

Diez maravedís. Sello cuarto, año de mil y seiscientos y cuarenta y cuatro.

En la ciudad de Toledo, a nueve de marzo de mil y seiscientos y cuarenta y cuatro años, ante mí, el escribano y testigos, pareció Antonio de Prado, autor de comedias residente en esta ciudad, y se obligó en favor de Toledo y de los señores don Inacio de la Palma, Juan Bernabé de Grijota, regidores, Melchor Ortís de Cisneros y Luis de Palma, jurados, sus comisarios, de hacer que hará las fiestas y representaciones del día del Santísimo Sacramento deste año de cuarenta y cuatro, en esta manera: que el jueves, día del Corpus por la tarde, en el sitio que es costumbre, representando con su compañía dos autos, dos loas, dos entremeses, dos bailes y un sarao, y por la mañana en la plaza de Zocodover, o en dos sitios donde se señalare, de manera que por la mañana se ha de hacer dos representaciones en dos partes, y ansimismo el viernes siguiente por la tarde representará los dos autos que ha de representar el jueves en la forma y cómo se hubiere hecho el día de la fiesta por razón de lo cual se le han de pagar siete mil y cuatrocientos reales, por cuenta de los cuales ha recebido seis mil y ochocientos reales, de que el dicho Antonio de Prado se otorgó por contento y pagado a su voluntad, sobre que renunció las leyes de la paga y la resta después de acabada la fiesta.

Y la dicha fiesta ha de hacer con las personas siguientes: el dicho Antonio de Prado, Juan de la Calle, Sebastián de Prado, su hijo; Frutos Bravo, gracioso; Juan de Ecurigüela y Carmona; Isidro, músico de arpa; Jusepe, músico; Reimundo, Rafael y Flores, Mariana Vaca, Jusepa Lobaco, Rufina, Justa, Antonia y Úrsula, y si fuere necesario otra mujer, la dará.

Y los dichos señores comisarios le han de dar los autos, entremeses, bailes y saraos para que lo estudien treinta y cuatro días antes del Corpus.

Y el dicho autor ha de poner y vestir la compañía de todo lo necesario para autos, comedia y entremeses, bailes y saraos, de trajes y lo demás que fuere necesario, y ha de estar en esta ciudad la dicha compañía treinta y cuatro días antes del Corpus para poder estudiar, pena de veinte ducados por cada día que faltare, aplicados para el Hespital del Rey, y todavía será apremiado a ello, y si los dichos señores comisarios quisieren que la dicha compañía esté en esta ciudad el día de Pascua de Resurresión deste año, tenga obligación el dicho Antonio de Prado a estar desde el dicho día de

${ }^{2}$ Como se ve, en un mes se termina el auto. Según el autógrafo de La humildad coronada, representado el 17 de marzo de 1644, se dice que se hizo para la fiesta del S. S. de la ciudad de Toledo, y allí "ábrese el arco en medio de las dos torres y bajan dos ángeles" (ed. I. Arellano, Kassel, 2002, p. 62). Igualmente, "se han descubierto los jardines y corrido las fuentes. A este tiempo han de salir de las dos torres últimas todos los que pudieren" (p. 127). 
Pascua hasta el día del Corpus, sin faltar día, pena de quinientos ducados para el Hespital del Rey, demás de ser apremiado dello.

Iten dará la muestra en el corra[l] el día que los dichos señores comisarios le señalaren.

Iten si los señores comisarios quisieren que la fiesta que se ha de hacer el viernes siguiente al día del Corpus, se haga en otra parte en lugar de la que se había de hacer en el mismo teatro del jueves, le ha de hacer la compañía en la parte que le ordenaren, y si faltare algún representante, ha de poner uno en su lugar a satisfación de los señores comisarios, y el dicho autor ha de poner los bailes y música que pidieren los autos, entremeses y bailes y saraos.

Las cuales dichas fiestas se hubo de hacer en la forma susodicha a el dicho Antonio del Prado, pena de quinientos ducados para el Hespital del Rey desta ciudad, en que se da desde luego por condenado demás de que a su costa se pueda buscar y traer quien haga la dicha fiesta, caro o barato, y lo que más costare se obliga de lo pagar.

Testigos: don Pedro Bazán, don Pedro Calderón y Francisco Ortís de Angulo, vecinos de Toledo. Don Ignacio de la Palma, Juan Bernabé de Grijota, Luis de la Palma, Melchor Ortiz de Cisneros. Antonio González de Prado.

\section{9. [8 de abril de 1644. Taibicado del tablado].}

Diez maravedís. Sello cuarto, diez maravedís, año de mil y seiscientos y cuarenta y cuatro.

En la ciudad de Toledo, a ocho días del mes de abril de mil y seiscientos y cuarenta y cuatro años, ante mí, el señor oidor Esteban de Valderrama, como principal, y Alonso Rodríguez, su fiador, ambos vecinos desta ciudad, maestros de albañilería y pintores.

Se obligaron en favor de los señores don Inacio de la Palma, regidor, y Juan Bernabé de Grijota, y de los demás comisarios de la fiesta del Santísimo Sacramento deste año, de que taibicarán todo el primer cuerpo del tablado que se ha hecho para la representación y las vallas de las torres y pasadizos dellas de torre a torre, por la parte de afuera y adentro que mira a las casas de los ayuntamientos, y las gradas desde el suelo a las barandillas lo que tocare por la parte de adentro y que mira a las plazas, todo de altura desde el suelo hasta que fise con las barandillas que se hubieren de poner en toda la fábrica del tablado y torres, y a donde no hubiere barandillas lo ha de taibicar hasta que fise con los lienzos, y el dicho taibique ha de ser sencillo, acabado de yeso puro y dado de llana y entomizado, y luego se le ha de dar de cal revocándolo de cintas de cantería y salpicado frunzido, y por toda la dicha obra que se ha de comenzar desde hoy y se ha de [a]cabar ocho días del día del Corpus, se le han de pagar mil reales de toda costa de manos y materiales, y el despojo que quedare acabada la fiesta, ha de ser para los dichos maestros, los cuales se obligan de tenerlo en pie y reparado los dos días de jueves y viernes que sean la dicha fiesta, y por cuenta de los dichos mil reales se le han de pagar luego de contado cuatrocientos reales, y para después en ocho días otros doscientos reales, y la resta como se fuere acabando la obra, y de los cuatrocientos reales que se les dan luego, se otorgarán por [...]. 
Don Ignacio de la Palma, Juan Bernabé de Grijota, Alonso Rodríguez, Esteban de Valderrama.

10. [9 de abril de 1644. Obligación de Juan Vidal de asistir con el clarín].

Diez maravedís. Sello cuarto, año de mil y seiscientos y cuarenta y cuatro.

En la ciudad de Toledo, a nueve de abril de mil y seiscientos y cuarenta y cuatro años, ante mí, el escribano y testigos, pareció Juan Vidal, vecino de Bargas, y se obligó en favor de Toledo y de sus comisarios de asistir con el clarín el día de la muestra del día del Santísimo Sacramento, y el jueves, día del Corpus, y el viernes siguiente, en los autos y comedias que se hicieren, y hará todo lo que tuvo obligación de hacer el año pasado, por razón de lo cual se le han de pagar doscientos y cincuenta reales, más o menos, de lo que se le dio el año pasado, por cuenta de lo cual recibió cien reales, de que se otorgó por contento y pagado a su voluntad, sobre que renunció las leyes de la paga y la resta en acabando la fiesta.

Testigos: Domingo Rodrigues y Alonso Peres y Juan Días, vecinos de Toledo. Don Ignacio de la Palma, Juan Vidal.

\section{1. [11 de mayo de 1644. Obligación de asistir de unos ministriles].}

Diez maravedís. Sello cuarto, año de mil y seiscientos y cuarenta y cuatro.

En la ciudad de Toledo, a once de mayo de mil y seiscientos y cuarenta y cuatro años, ante mí, el escribano y testigos, parecieron Juan Lopes del Mar y Alonso del Castillo, Alonso Martines de Vergara, Juan Lopes el mozo y Juan Grabiel de Noriega. Y se obligaron en favor de Toledo y del señor don Inacio de la Palma, Juan Bernabé Grijota, regidores, y Luis de Palma y Melchor Ortis de Sisneros, jurados, comisarios de las fiestas del Santísimo Sacramento, de asistir y que asistirán cuatro ministriles el jueves y viernes de la fiesta y el día del ensayo, y en las demás partes que se les ordenare en las dichas fiestas en los dichos días, por razón de lo cual les ha de pagar quinientos reales luego de contado, de que se otorgaron por contentos, y sobre la entrega renunciaron las leyes de la entrega y paga y le dieron carta de pago en bastante forma.

Testigos: Juan Días y Alonso Peres y Juan de Talavera, vecinos de Toledo, Alonso del Castillo, Juan López, Alonso Martín de Vergara, Juan Gabriel, Juan López de Noriega, el mozo.

\section{2. [1644. El autor Pedro de Covaleda escribe al Ayuntamiento de Toledo sobre la representación de una comedia].}

Pedro de Covaleda, autor de comedias por su Majestad, digo que yo quiero servir a V. S. con la Comedia de Tobias, y para ella y otras que tengo de representar se han de hacer algunas apariencias. 
A V. S. suplico mande dar licencia para que se hagan como se han hecho con los demás autores, en que recibiré merced.

Pedro de Covaleda.

\section{3. [1644]. Tablado y demás fiesta de la del Santísimo del año de 1644.}

Condiciones con las cuales se ha de hacer la armazón de madera del teatro de las fiestas del Santísimo Sacramento deste año de 1644 en esta ciudad de Toledo, y son las siguientes:

1. Primeramente es condición que el tablado de la representación se ha de plantar en el sitio que enseña la planta hecha para el dicho efeto, con las medidas de ancho, largo y alto que se ve en el alzado o perfil, haciéndole en esta conformidad: en el suelo de dicho tablado, habiéndole armado con sus piezas carreras, encima de ellas se ha de sentar un maderamiento en la misma conformidad que enseña el desnudo para que se dejen escutillones para las luces, transmutación de los cuadros del jardín y calles de él; y todo el dicho suelo ha de quedar entablado de tabla de chilla juntada sin acepillar, y en él hechos 16 escutillones y los cuatro cuadros conforme a la traza, y el escutillón de la fuente de en medio y crucero de las calles de los cuadros del jardín.

2. Es condición que las cuatro torres se han de armar en esta conformidad: en cada esquina se ha de plantar un pie derecho o alma enterizo de todo el alto de las torres y echar sus dos suelos alfarjiados y entablados al alto de las cornisas, o al que se señalare dejándolo fortalecido en la conformidad que ordenare el maestro mayor que asistirá a ordenar lo que convenga.

3. Iten es condición que de torre a torre desde las de en medio a las de los lados, se han de hacer dos pasadizos del ancho y largo que enseña la traza, y al mismo alto del tablado enmaderado y entablado por la parte de arriba con la tabla juntada sin acepillar, y por la parte de abajo ha de quedar muy bien apeado con sus pies y carreras para que se pueda tabicar de ladrillo, dejando los güecos de los arcos que enseña la traza.

4. Iten es condición que desde las dos torres últimas hasta el ayuntamiento se han de hacer los andenes de tablados que enseña la traza y de la manera y forma que en ella se ven; el suelo de ellos al mismo alto por la parte de delante que los de los pasadizos y tablado, y por la parte de atrás más levantados para que echando unos tablones en forma de gradas con sus asnillos a trechos sirvan de asientos; la fortificación de debajo de dichos andenes han de ser con pies y carreras, tornapuntas y riostras, dejando los güecos de los arcos como la traza lo enseña.

5. Iten es condición que se han de hacer en las cuatro torres en cada una su escalera como se ven en la traza, o las ordenare el maestro mayor según fuere necesario para el desembarazo de las torres; y en ellas sus atajos o antiparas de madera que se ordenaren conforme a los acaecimientos que se pueden ofrecer.

6. Iten es condición que entre las dos torres de en medio se ha de hacer el arco que enseña la traza, de la mesma suerte que en ella se ve, fortificando las dos dichas torres con las dos vigas que se han de echar en el lugar de las 
cornisas, que sean enteras de todo el largo si es posible, y en la clave del arco ha de quedar por la parte de abajo un escutillón para la apariencia que se dirá adelante.

7. Iten es condición que se ha de hacer el frontisficio que enseña la traza y remate de él.

8. Iten es condición que se han de hacer las armazones de tablados y gradas y vallas que se hicieron el año pasado encima y debajo del pretil del Ayuntamiento.

9. Iten es condición que se han de hacer todas las verjas o barandillas que enseña la traza, así en los corredores por uno y otro lado como en los de delante de las torres y lados del tablado, y como los de los andenes de delante de los tablados que escuadran las dos plazas del teatro, todas ellas de tabla de chilla de la hechura que ordenare el maestro mayor con sus soleras o mesas altas y bajas por dos haces, y estas verjas y soleras han de estar acepilladas.

10. Iten es condición que se han de hacer los remates de las cuatro torres de la misma manera que enseña la traza, y el cómo se hayan de obrar ha de ser ordenado por el maestro mayor.

11. Iten es condición que se han de hacer todos los bastidores para vestir las cuatro torres, los del arco por la parte de abajo y cuatro enjutas, los de los dos lados del frontisficio y los dos altos del mismo frontisficio.

12. Iten es condición que se han de hacer todas las máquinas de tramoyas y apariencias que contiene la memoria hecha por don Pedro Calderón, que está firmada de los señores comisarios y maestro mayor, que se entiende la armazón de madera de ellas porque el vestirlos no ha de correr por cuenta del carpintero, mas de tan solamente el armarlas de madera y hacer las máquinas de tornos, canales, poleas y todo lo demás perteneciente para dejarlas corrientes y usuales.

13. Iten es condición última que el maestro carpintero ${ }^{3}$ que de la dicha obra de la fiesta del Santísimo Sacramento se encargare, se ha de obligar a hacer todo lo arriba referido a toda costa de manos y materiales, como son todo género de madera, clavazón, esparto, cáñamo, yerro, y poner todo género de pertrechos de herramientas sin que se le haya de dar más de tan solamente el dinero en que se concertare a los plazos que se pusiere en el concierto, y también se ha de obligar a darlo todo acabado para el tiempo que se le señalare y para el cumplimiento de dar la satisfación que los señores regidores y comisarios de las fiestas pidieren; y se advierte que en todo lo que se hubiere de hacer necesariamente para el cumplimiento de tablado de la representación, torres, corredores, andenes de tablados, tablados de ayuntamiento, barandillas, escaleras de torres, arco, frontisficio, remates, tableros de armas, postigos, suelos, bastidores y tronos y todo género de apariencia, escutillones, transmutaciones y todo lo demás que se ofreciere para la dicha fiesta, eceto pintura y figuras y adornos de jardín, ha de correr por cuenta del maestro de carpintería sin que se le haya de pagar demasía ninguna, y dado caso que se ofresca hacer alguna otra cosa que no se haya puesto en estas condiciones, se haya de hacer sin contarse por demasía cualquiera cosa que ella sea, ajustándose en que no haya de pasar de precio de trescientos reales más de lo que montare el concierto

${ }^{3}$ Interlineada esta palabra. 
asentado de toda la dicha obra, y esto se hace por evitar tasaciones de demasías, que es de donde proceden pleitos y para que se sepa el gasto que ha de tener la dicha obra sin más dependencia de en lo que estuviere concertada.

Iten es condición que el maestro de carpintería que hubiere o se encargare de la dicha obra, ha de ser obligado a poner gente que jueguen las tramoyas al tiempo que se hubiesen de obrar en entrambos días.

Iten es condición que las tramoyas que llevare el autor para hacerlas en el corral de la comedia se le hayan de volver en no habiéndolas menester en el corral para efeto de las fiestas que representare en Toledo.

Condición que se le han de dar guardas y luces para este año, jueves y viernes en la noche.

Iten es condición que toda la madera que se gastare en la dicha fiesta se le devolverá aunque esté pintada, escepto bastidores, andenes de calles [?] y todo género de bulto de figuras.

Iten es condición que aunque los corredores está puesto en la condición que trata de esto, hayan de ser las verjas de tablas con so[le]ras ${ }^{4}$ y antepechos; solo se muda en ésta que las dichas verjas ha de estar obligado dicho Pedro López a que sean torneadas de el altor que el señor maestro mayor señalare.

[Tachado: Iten es condición que por precio de la ejecución de estas condiciones por toda la costa de ellas.]

Testigos: Don Pedro Bazán y Diego de Toledo y Melchor Ortiz de Cisneros, comisario, vecinos de Toledo; y lo son los otorgantes, a los cuales yo, el escribano doy fe que conozco. Don Ignacio de la Palma, Juan Bernabé de Grijota, Luis de la Palma del Águila, Melchor Ortiz de Cisneros, Pedro López Briceño.

\section{4. [1645. Memoria de apariencias que Rojas manda a Toledo para que se representen dos autos suyos. Autógrafa].}

Apariencias del acto de La viña de Nabot, que es el primero que se ha de representar.

- Un pescante, en que ha de bajar un ángel.

- Un ídolo de pasta o madera, con seis blandones de plata, con seis hachas. Póngase en parte que se pueda hundir.

- Dos montañas de verde a los dos lados del teatro que no estorben la fachada. En la una haya un becerro que se pueda hundir; la otra ha de ser una cuesta que pueda rodar por ella una mujer, y hagan las dos montañas iguales para que hermoseen.

- Una nube que ha de llover fuego que caiga sobre el ídolo, que se ha de hundir cuando ella le despida.

- Otra que después despida agua en forma de lluvia, y sea de manera que no caiga sobre los vestuarios de los representantes el agua, que los manchara los vestidos.

\footnotetext{
${ }^{4}$ Cortado en el documento, no se puede leer la palabra.
} 
- Hase de hacer una viña con treinta cepas y, si no pudieren ser tantas, podrán nivelarla con menos; cada cepa tenga pámpanos que se pueden traer de las viñas, y en una vid que esté en medio, que sea la mayor, haya un cáliz con un pan. Deste cáliz salgan tantas cintas carmesíes de las angostas como hubiere cepas. Si se pudiere hacer esta viña de manera que no parezca la traza a la de los jardines del año pasado, será mejor, porque no se ha de descubrir hasta el fin del auto, y me holgaría que se hiciese alguna novedad. El maestro podrá arbitrar en esto.

- Para acabar el auto ha de bajar un carro con dos caballos y un cochero que ha de llevar una figura. Ha de ser de fuego.

Apariencias del acto intitulado Galán, discreto y valiente ${ }^{5}$.

- Una valla en que han de tornear cuatro aventureros, que ha de estar suelta, y un representante la ha de fijar y clavar, que se ha de volver cruz, y en ella ha de subir una figura hasta lo más alto que sea posible.

- De los dos lados de los vestuarios han de salir dos ángeles con dos cipreses y han de subir llevando la cruz en medio; cada ciprés ha de llevar una ángel en una punta.

- Hase de hacer un rótulo que diga: INRI en una tabla que tenga cerca de media vara de largo y de ancho ocho dedos.

- Ha de haber cuatro palenques por cuatro partes para la entrada de los aventureros.

- Una calavera que se ha de poner un representante.

[Acompaña un dibujo de su propia mano que representa el escenario.]

\section{5. [1645. Memoria y condiciones cómo se ha de hacer el teatro para las fiestas del Santísimo Sacramento].}

Diez maravedís. Sello cuarto, diez maravedís, año de mil y seiscientos y cuarenta y cinco.

Memoria y condiciones cómo se ha de hacer el teatro para las fiestas del Santísimo Sacramento para este año de 1645 en la plaza del ayuntamiento desta ciudad de Toledo, son las siguientes:

Primeramente, es condición se ha de hacer un tablado de cuarenta y siete pies i medio en cuadrado, en que dentro del dicho sitio se ha de levantar la obra y fábrica que demuestra la traza, y ha de tener de alto el dicho tablado por la parte más baja cinco pies guardando el nivel que le cupiere por la parte de abajo.

Es condición que todo este tablado ha de estar apeado todo alrededor de pies, habiendo de estar uno de otro seis pies para que se pueda tabicar

\footnotetext{
${ }^{5}$ Rojas ha tachado la palabra valiente en segundo lugar, que había escrito primero, de tal manera que el título Galán, valiente y discreto se posterga a favor de Galán, discreto y valiente, que se prefiere.
} 
todo alrededor dejándolo a plomo, escuadría [a] cuerda tirada, entablado por encima todo de chilla deshilada, dejando escutillones en los tres lienzos del dicho teatro para las luces, hasta veinte, o los que más convengan.

Es condición encima deste teatro se han de levantar tres suelos al alto que dimuestra la traza, que tiene el primer suelo de alto diez y ocho pies con gruesos de todas maderas, y el segundo suelo ha de tener once pies de alto con todas maderas, y tercer suelo ha de tener de alto con todas maderas diez pies, y todos los dichos suelos han de tener en su planta en cuadrado doce pies.

Es condición se han de poner en todos los suelos de las torres y debajo del teatro escaleras para subir y bajar, y todos los dichos suelos han de estar entallados.

Es condición que encima del teatro donde se representa se han de poner verjas todo elrededor, fuera de los maci[z]os de las torres.

Y en el segundo suelo se han de poner por la parte de la vista de Ayuntamiento, se han de poner tres balcones volados, lo que volaren las cornisas de verjas torneadas, con tres bolas de remate en cada balcón, y por la parte que mira a la iglesia ha de llevar sus paños de verjas de cabo a cabo de toda dicha fábrica, y éstos no han de ser volados, y estas verjas de los balcones han de ser conforme demuestra la traza, que han de ser inmitados como si fueran de yerro.

Es condición que en el tercer suelo se han de poner antepechos de verjas todo alrededor entre pedestral y pedestral, tomadas todas las dichas verjas y de una labor todo correspondiente.

Es condición que todos los dichos suelos declarados han de ir muy bien apeados y arrostrados con toda satisfación.

Es condición que en el primer suelo de las dos torres se han de hacer dos bastidores para cada una, y son para las dos esquinas de la parte de atrás porque las otras dos esquinas de la parte de adentro han de ir vestidas con sus pilastras y cortinas, con el adorno que demuestra la traza. Y en el segundo suelo se han de hacer cuatro bastidores para cuatro reyes de armas para los sitios que demuestra la traza. En el segundo suelo, digo en el tercero, se han de hacer doce bastidores para las dos torres, que son los tres testeros que cada una demuestra por la parte de afuera, y en los demás huecos que no llevan bastidores de todos los dichos suelos, se han de vestir las olmas [?] con sus pilastras y demás adorno que demuestra la traza, y por la parte de adentro oscurecidos estos suelos con cortinas, las que dieren los caballeros comisarios.

Y encima de todos los dichos suelos se han de poner los remates difiniciones que demuestran la dicha traza, haciendo doce bastidores, que son tres para cada una de las virtudes y seis para el frontespicio, y debajo de cada una de las dos virtudes ha de haber en lugar de pedestral dos escocias.

Es condición que se han de hacer seis tableros para en que se han de pintar las dos águilas imperiales, y los otros cuatro para pintar cuatro figuras que están sobre el frontispicio, y el cáliz con su arco que demuestra la traza ha de estar a la haz del frontispicio de la parte de la representación, y por el otro lado en lugar del cáliz, se ha de pintar sobre las águilas una corona imperial.

Es condición que en los suelos que dimuestra en el ventanaje y postigos arcos, han de ser bastidores desde encima de las impostas hasta llegar 
a los cornisamentos de bastidores, y desde allí abajo ha de ser del dicho cortinaje, como está dicho en otra condición, esceto que a donde hubiere apariencia no podrá llevar bastidor sino cortina.

Es condición que en los dos arcos de en medio del primer suelo, encima del teatro, han de estar trasparentes y alfarjeados con la propia vuelta, de manera que hagan dos cañones de bóveda que vengan a descansar sobre las dos pilastras de en medio y las caberas de los lados de las dos torres.

Es condición que ha de labrar y poner todas las pilastras e madera conforme la labor y dibujo de la traza. Y asimismo todos los paños de verjas que van en traza en los antepechos y alrededor del teatro de la representación, se hayan de hacer y poner todas correspondientes las unas a las otras.

Es condición que se han de poner las dos figuras de las dos virtudes, las que dieron los señores comisarios, de manera que no ha de correr por cuenta del maestro o maestros que se encargaren de la dicha pintura, ni figuras, ni colgaduras, ni verduras, no más de lo tocante a madera a la dicha fábrica en blanco.

Es condición que a los dos lados del teatro, en el medio del testero de las dos torres, en la superfiz de empedrado, se han de sentar dos postigos, cada uno con su cerradura y llave, donde sea con las vías para el reparo de la gente, en esta forma: de la parte de las casas del señor deán, desde donde se ha de sentar el postigo a cuerda tirada hasta encima de la primera bóveda de enfrente del escritorio de Rodrigo de $\mathrm{Oz}$, se ha de hacer una valla de dos barras de alto, entablado todo en todo dicho largo; y de la parte de arriba del dicho teatro donde se ha de poner el dicho postigo, se ha de poner esta valla que llegue hasta la fábrica del ayuntamiento, donde se ha de poner otro postigo con su llave y ha de ser la baja alto de la otra de abajo, que son seis pies, y ésta no a de ser a cordel tirado, sino que haga rincón hasta doce pies porque quepa más gente.

Es condición que en la delantera del ayuntamiento se ha de armar un tablado llano de nueve pies de ancho y cinco pies de alto y cincuenta pies de largo.

Es condición que en el corredor de piedra del ayuntamiento se ha de armar de gradas seis güecos de los arcos que se suelen armar de cinco gradas de alto, y al pie de las dichas gradas se ha de hacer una tarima de un pie de alto y de todo el largo de las gradas que se armaren, y de ancho desde el pie de la grada hasta topar con los antepechos de piedra, y la entrada para estas gradas se ha de hacer por do ordenaren los señores caballeros comisarios, eceto si mandaren quitar alguna pared o reja o postigo, ha de correr por cuenta de los señores comisarios el mandallo sentar por su cuenta.

Es condición que después de acabadas las fiestas se ha de llevar el maestro o maestros que de esta obra se encargaren, todos los materiales de cualquier estado o condición que tuviere el dicho teatro, eceto los cortinajes de las ventanas y colgaduras y los bastidores que tuvieren lienzos pintados, porque éstos serán para los señores comisarios porque cualquier género de madera, aunque esté pintada, ha de ser para quien hiciere la dicha obra.

Al pie de las gradas, adonde se sienta el ayuntamiento en la tarima del suelo, se ha de hacer otra grada que levante medio pie más que la de abajo porque se pueda poner otra hilera de [e]scaños.

Y en cuanto suelos de las torres, en el segundo suelo a donde hobiere balcones, esceto a donde van pintados los reyes de armas, ha de ir todo calado. 
Y en el tercero suelo, por la parte que cae a la santa iglesia, en todo el frontero y los dos testeros, han de ser bastidores.

Es condición que si fuere menester agrandar el te[atro de]? las casas de las comedias, lo ha de agrandar lo que fuere menester para la muestra.

Es condición que se ha de hacer los tablados que fueren menester en las calles adonde se pone la música para cantar o danzar mientras pasa la procesión, a donde señalaren los señores comisarios, en tres partes distintas.

Es condición que los dos balcones que tienen los señores comisarios para ver las fiestas se han de atajar con tablas.

Es condición que si fuere menester para los autos de [e]ntremeses hacer algunas vallas o palenques para algún torneo o para otra [a]pariencia, se ha de hacer.

Es condición que debajo del tablado se ha de hacer un aposento con su puerta y cerradura para que se guarde allí lo que fuere menester.

Es condición que lo que toca a [a]pariencias, no corren por ninguna obligación en el concierto hecho de las apariencias.

Es condición que el maestro o maestros que de esta obra se encargare, no se le ha de dar más de los maravedís que se concertare, y si hiciera alguna menorías de las condiciones declaradas, se le haya de rebajar lo que fuere justo, y si hiciere alguna demasía, se le hayan de satisfacer.

\section{6. [1645. Obligación del escultor Eugenio Rodríguez ${ }^{6}$.}

Escultor.

Dies maravedís. Sello cuarto, diez maravedís, año de mil y seiscientos y cuarenta y cinco.

Eugenio Rodrigues, escultor, vecino de Toledo, se obliga:

-A amoldar de madera los pedrestales según está en la traza de el teatro.

-Iten para la cornisa del primer cuerpo, ha de vaciar las metopas y teglifos y gotas de pasta.

-Iten en el segundo cuerpo, se han de hacer veinte y cuatro bichos que han de ser vaciados de pasta, y en este mismo cuerpo se han de vaciar cuarenta y ocho vasos y capiteles jónicos.

-En el tercero cuerpo se han de vaciar cuarenta y ocho capiteles y vasos de pasta, que son con las molduras de madera quinientas piezas, diez más a menos.

Y está concertado todo en mil y cien reales de vellón, y a de poner todo lo necesario para el vaciado, menos la madera, que a de dar para el material Pedro López, carpintero, y lo dorado y pintado ha de correr por cuenta del pintor y no del susodicho.

[Al margen: 1100 reales.]

${ }^{6} \mathrm{El}$ documento se copia dos veces, una con la letra del escribano del Ayuntamiento y otra que parece de la propia mano del escultor, tal y como ocurre con las memorias de apariencias de Rojas. 
17. [1645. Memoria y condiciones de la obra tocante a la pintura del teatro].

Diez maravedís. Sello cuarto, diez maravedís, año de mil y seiscientos y cuarenta y cinco.

Memoria y condiciones de la obra tocante a la pintura del teatro de las fiestas del Santísimo Sacramento que se han de hacer en la plaza del Ayuntamiento desta ciudad, a este año de 1645, son las siguientes:

Primeramente, es condición que el maestro o maestros que se encargaren de la dicha pintura han de fingir de berroqueño almodillado, conforme demuestra la traza, todo el teatro alrededor y torres, desde el superficie del suelo hasta el suelo o madero del teatro de la representación.

Es condición que se ha de adornar y vestir todo este dicho teatro con la obra y colores y difiniciones de todos remates y balcones, todo género de verjas, de antepecho y los acheros que se pusieren, de manera que quede vestido todo el teatro y torres, todas las fachadas de todas partes de dicha fábrica de las dichas colores que demuestra la traza, porque no ha de quedar nada que vestir por ser todo pintado, eceto los güecos donde hobiere cortinas.

Y asimismo se han de pintar las figuras y águilas con sus tarjetas de las colores y obra que demuestra la traza.

Es condición que los capiteles y basas y trelifos y metopas han de ser de doradura, y asimesmo se han de dorar las bichas, lo que le cupiere que sea de doradura.

Es condición que en la segunda y tercera cornisa, en los frisos, se han de fingir unos grutescos.

Y es condición que donde hubiere rejas fingidas, que en las baraustes, en las molduras, ha de ser de doradura.

Y ansimesmo en los balcones ha de ser lo mismo.

Juan de Toledo, pintor.

\section{8. [8 de marzo de 1645. Concierto de ministriles para la fiesta del Corpus].}

Diez maravedís. Sello cuarto, diez maravedís, año de mil y seiscientos y cuarenta y cinco.

En la ciudad de Toledo, ocho días del mes de marzo de mil y seiscientos y cuarenta y cinco años, ante mí el escribano mayor, Juan López del Mar, vecino desta ciudad, por sí y prestando caución por Juan Gabriel de Noriega y Alonso Martín de Vergara, Jerónimo Ramírez y Juan López Belmar, el Mozo, y Domingo Rico, ministriles, vecinos de Toledo, para que estarán y pasarán por lo que se concertara en esta escritura, se obligó en favor de los señores comisarios de la fiesta del Santísimo Sacramento deste año, de que asistirán cuatro ministriles el jueves y viernes de la fiesta del Santísimo Sacramento y el día del ensayo, y en las demás partes que se les ordenare en las dichas 
fiestas en los dichos días, por razón de lo cual se les han de pagar quinientos reales, que confiesa haber recibido del señor jurado Diego Sánchez de la Puebla, comisario de la fiesta, de que se da por contento.

Joan López del Mar.

19. [27 de mayo de 1645. El autor Pedro Ascanio se obliga a representar en Toledo los dos autos del Corpus].

Autor de comedias. Obligación de la fiesta. 1645.

Dies maravedís. Sello cuarto, diez maravedís, año de mil y seiscientos y cuarenta y cinco.

En la ciudad de Toledo, a veinte y siete días del mes de mayor de mil y seiscientos y cuarenta y cinco años, ante mí el escribano pareció presente Pedro de Ascanio, autor de comedias por su Majestad, y se obligó a favor del señor Pedro Fernández de Loaísa y don Gaspar de Cepeda, regidores, y don Francisco de Rivadeneira y don Pedro Sánchez de la Puebla, jurados de Toledo, comisarios de la fiesta del Santísimo Sacramento deste presente año, de hacer y que hará las fiestas representaciones del día del Santísimo Sacramento deste año de cuarenta y cinco en esta manera que el día del Corpus por la tarde en el sitio que es costumbre representar con su compañía dos autos, dos loas, dos entremeses, dos bailes y un sarao y por la mañana en la plaza de Zocodover o en dos sitios donde se le señalare ha de hacer dos representaciones en dichas dos partes y ansimismo el viernes siguiente por la tarde representará los dos autos que ha de representar el jueves en la forma y como se hubiere hecho el día de la fiesta por razón de lo cual se le dará y pagará de contado por el dicho jurado don Pedro Sánchez de la Puebla como tal comisario siete mil y cuatrocientos reales en moneda de vellón de que el dicho Pedro de Ascanio se dio por contento, por lo que recibe realmente con efeto ... la entrega, renunció las leyes de casación y dio dello carta de pago en forma.

Y los dichos señores comisarios le han de dar los autos, entremeses y bailes y saraos para estudiarlos. Y si los señores comisarios quisieren que la fiesta que se ha de hacer el viernes siguiente al día del Corpus se haga en otra parte en lugar de la que se había de hacer en el mismo teatro del jueves la ha de hacer la compañía en la parte que ordenaren los señores comisarios. Y la muestra general de los autos se ha de hacer el miércoles víspera del día del Corpus en el Mesón de las comedias, como es costumbre, con todo adorno, sin faltar en cosa alguna. Y en esta conformidad el dicho Pedro Ascanio se obliga a hacer con su compañía la dicha fiesta.

Pedro de Ascanio.

(Archivo Municipal de Toledo. Fondo histórico, caja 881.) 
